\title{
Size-specific concentrations of phlorotannins (anti-herbivore compounds) in three species of Fucus
}

\author{
Andrew Denton, A. R. O. Chapman, John Markham
}

Department of Biology, Dalhousie University, Halifax, Nova Scotia, Canada B3H 4J1

\begin{abstract}
Using the Folin-Denis assay, we demonstrated significant $(p<0.05)$ differences in phlorotannin concentrations among large and small individuals of Fucus vesiculosus. This finding correlates with previously published differences in grazing susceptibility among the 2 size-classes of plants. However, in 2 other species of Fucus (F. evanescens and $F$. spiralis), there were no significant differences $(p>0.05)$ in phlorotannin concentrations among size-classes. Therefore, concentrations of anti-herbivore compounds cannot explain different effects of grazers on large and small individuals of $F$. spiralis.
\end{abstract}

The existence of size-related escapes from herbivory in fucoids is central to the concept of intertidal vegetation structure proposed by Lubchenco (1980). According to this concept, the maintenance of a fucoid vegetation depends on the grazing activities of intertidal herbivores. These grazers are thought to remove competitively dominant ephemeral algae leaving grazer-resistant fucoids to flourish. However, grazer-resistance in Fucus vesiculosus is restricted to larger individuals of more than $3 \mathrm{~cm}$ length (Lubchenco 1980). Small specimens were soon eliminated by grazing activities of Littorina littorea, a large periwinkle. In order for a fucoid vegetation to develop, $F$. vesiculosus must pass through a grazing bottleneck - a period of greatest susceptibility when plants are small.

In contrast to the results obtained by Lubchenco (1980), Chapman (1989) showed that Fucus spiralis adults were susceptible to grazing by herbivores at natural densities. However, small F. spiralis abundance was not significantly affected by grazing.

Geiselman (1980) reported unpublished work by O. J. McConnell which showed that small $(<3 \mathrm{~cm}$ long) plants of Fucus vesiculosus contained very low concentrations (values not given) of phlorotannins which are anti-herbivore defence compounds produced by brown algae (Hay \& Fenical 1988). However, Geiselman found concentrations reaching $10 \%$ of dry weight in mid-thallus sections of adult $F$. vesiculosus. Lubchenco
(1980) suggested that the difference in phlorotannin concentrations accounts for the differing susceptibilities of small and large plants to the grazing of Littorina littorea. Is it also possible that large and small plants of $F$. spiralis have significantly different concentrations of phlorotannin which might relate to differing susceptibilities to grazing? We approached this question by measuring the phlorotannin concentrations in large and small specimens of $F$. spiralis. In addition, concentrations were measured in $F$. evanescens and $F$. vesiculosus. The null hypothesis in all cases was that phlorotannin concentrations were not significantly different among large and small plants of the same species.

Specimens of Fucus spiralis and $F$, evanescens were collected from a NW Atlantic shore at Cranberry Cove, Nova Scotia, Canada. F. vesiculosus specimens were collected from a nearby site, Terrance Bay. Collections were made at low tide on 13 October 1989 and returned to the laboratory in an insulated container. Specimens were immediately frozen at $-70^{\circ} \mathrm{C}$. Before extraction of phlorotannins, specimens were partially unfrozen to allow separation of plants. Individual plant lengths were then measured. Batches of $0.5 \mathrm{~g}$ of plants classified as 'small' $(<3 \mathrm{~cm}$ total length) were transferred whole to a mortar where they were ground to a fine powder in liquid nitrogen. In the case of 'large' (> $10 \mathrm{~cm}$ total length) plants, $0.5 \mathrm{~g}$ mid-thallus portions, including wing and midrib, were excised with a razor blade and ground in liquid nitrogen. In all cases we recorded the lengths of individuals used in the analysis Phlorotannins were extracted in re-distilled acetone from the ground powders. The extracts were evaporated under slight vacuum and the phlorotannins were then re-dissolved in distilled water. After centrifugation, the concentrations of phlorotannins in the supernatant were measured using the Folin-Denis colorimetric procedure (Ragan \& Jensen 1977). Purified high 
molecular weight polyphenol from $F$. vesiculosus was used as the reference compound.

Concentrations of phlorotannins in the 2 size categories of each Fucus species are shown in Table 1. In $F$. vesiculosus there were large significant differences in concentrations among large and small plants

Table 1. Fucus spp. Mean $\pm \mathrm{SD}(\mathrm{n}=10$ in all cases) concentrations ( $\%$ of dry weight) of phlorotannins in large and small specimens of 3 species. Lengths of plants (mean \pm SD) included in the analysis are also given. p-values refer to t-tests for signficant differences among large and small plants within species (see text for details)

\begin{tabular}{|c|c|c|c|}
\hline Species & $\begin{array}{l}\text { Length } \\
\text { (cm) }\end{array}$ & $\begin{array}{l}\text { Phlorotannin } \\
\text { conc. }\end{array}$ & p-value \\
\hline Fucus vesiculosus & $\begin{aligned} 32.51 & \pm 7.54 \\
1.85 & \pm 0.80\end{aligned}$ & $\begin{array}{r}12.83 \pm 4.00 \\
7.30 \pm 0.63\end{array}$ & 0.0001 \\
\hline Fucus spiralis & $\begin{array}{r}15.53 \pm 2.71 \\
1.69 \pm 1.01\end{array}$ & $\begin{array}{l}8.71 \pm 2.25 \\
7.57 \pm 0.81\end{array}$ & 0.2604 \\
\hline Fucus evanescens & $\begin{array}{r}32.07 \pm 5.62 \\
1.99 \pm 1.33\end{array}$ & $\begin{array}{l}7.01 \pm 1.45 \\
5.81 \pm 0.92\end{array}$ & 0.0513 \\
\hline
\end{tabular}

(2-tailed t-test, $\mathrm{t}=5.104, \mathrm{p}=0.0001, \mathrm{df}=18$, data angular transformed to stabilize variances). However, in the other 2 species of Fucus, there were no significant differences in concentrations among size categories $(F$. evanescens: $\mathrm{t}=-2.087, \mathrm{p}=0.0513 \mathrm{df}=18$; F. spiralis: $\mathrm{t}=1.162, \mathrm{p}=0.2604, \mathrm{df}=18$; data angular transformed in both cases).

The results support Lubchenco's (1980) contention that size-specific grazer resistance in Fucus vesiculosus is correlated with size-specific variation in anti-herbivore chemicals. However, this is not a general phenomenon for fucoid vegetation. In F. spiralis, the adult canopy is more susceptible to grazer damage than are juvenile plants (Chapman 1989), yet we found no significant difference in phlorotannin concentrations among plants in the 2 size groups. The relative grazersusceptibilities of large and small $F$. evanescens plants are not known, but in any case, phlorotannin concentrations were similar There was only a $20 \%$ difference among the means of large and small plants of this species and the difference was not statistically significant. However, it should be noted that the p-value $(0.0513)$ is quite close to statistical significance at the $95 \%$ level.

As the results presented here show, it is not possible to extrapolate from the relationship between Fucus vesiculosus and its grazers to construct a general con-

This note was presented by Dr G.C. Harding, Dartmouth, N.S., Canada cept of the maintenance of fucoid vegetation structure. Although there is physiognomic homogeneity among the intertidal zones occupied by the several species of Fucus occurring in the NW Atlantic, each species has unique physiological properties (Chapman \& Johnson 1990) and unique biotic interactions (Chapman 1989. Barker \& Chapman 1990). Similarly, the grazer guild varies quantitatively and qualitatively through the fucoid vegetation (Barker \& Chapman 1990). There cannot, therefore, be a single concept of community organizing processes applicable throughout the broad belt of brown rockweeds which dominates the intertidal zone

Finally, it should be pointed out that the Folin-Denis assay used here measures only total phenolic concentration. It does not discriminate different polyphenol fractions with high and low molecular weights. It is possible that the proportions of these 2 fractions are important in determining grazer deterrence, but this remains to be tested.

Acknowledgements. We thank Dr Mark Ragan for providing purified phloroglucinol samples and initial training for J. M. The work was funded by grant A6497 from the Natural Sciences and Engineering Research Council of Canada.

\section{LITERATURE CITED}

Barker, K. M., Chapman, A. R. O. (1990). Feeding preferences of periwinkles among four species of Fucus. Mar Biol. (in press)

Chapman, A.R.O. (1989). Abundance of Fucus spiralis and ephemeral seaweeds in a high eulittoral zone: effects of grazers, canopy and substratum type. Mar. Biol. 102 $565-572$

Chapman, A. R. O., Johnson, C. R. (1990). Disturbance and organization of macroalgal assemblages in the northwest Atlantic. Hydrobiologia 192: 77-121

Geiselman, J. A. (1980). Ecology of chemical defenses of algae against the herbivorous snail, Littorina littorea, in the New England rocky intertidal community. Ph.D. thesis, Massachusetts Institute of Technology/Woods Hole Oceanographic Institution

Hay, M. L., Fenical, W. (1988). Marine plant-herbivore interactions: the ecology of chemical defense. Ann. Rev. Ecol. Syst. 19: 111-145

Lubchenco, J. (1980). Littorina and Fucus effects of herbivores, substratum heterogeneity, and plant escapes during succession. Ecology 64: 1116-1123

Ragan, M. A., Jensen, A. (1977). Quantitative studies on brown algal phenolics. I. Estimation of absolute polyphenol content of Ascophyllum nodosum (L.) Le Jol and Fucus vesiculosus L. J. exp. mar Biol. Ecol. 34: 245-258

Manuscript first received: August 5, 1989

Revised version accepted: April 23, 1990 